\title{
Short Communication: The Prevalence and Patterns of Palmaris Longus Muscle Absence in an Iranian Population
}

\author{
Mehdi Forouzesh' ${ }^{1}$ (D), Abdolrazagh Barzegar ${ }^{1}$ (D) Fardin Fallah $^{1 *}$ iD
}

1. Legal Medicine Research Center, Legal Medicine Organization, Tehran, Iran.

\begin{tabular}{|c|c|}
\hline $\begin{array}{l}\text { Use your device to scan } \\
\text { and read the article online }\end{array}$ & Citation: Forouzesh M, Barzegar A, Fallah F. The Prevalence and Patterns of Palmaris Longus Muscle Absence in an Iranian \\
\hline 口ifipa & $\begin{array}{l}\text { Population. International Journal of Medical Toxicology and Forensic Medicine. 2019; 9(4):279-282. https://doi.org/10.32598/ } \\
\text { ijmtfm.v9i4.26515 }\end{array}$ \\
\hline 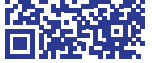 & dol' https://doi.org/10.32598/ijmtfm.v9i4.26515 \\
\hline
\end{tabular}

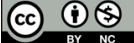

Article info:

Received: 03 Mar 2019

First Revision: 15 Mar 2019

Accepted: 25 Jul 2019

Published: 01 Oct 2019

\section{Keywords:}

Absence, Cadaver, Palmaris Longus muscle, Sex, Side

\begin{abstract}
Palmaris Longus (PL) is a muscle of the forearm, i.e., not functionally necessary and does not exist in all people. It is a choice for tendon graft and investigating its prevalence is of clinical importance. During April-October 2009, 102 cadavers (78 males, 24 females) were bilaterally necropsied for PL exploration in Zanjan City, Iran. PL Absence (PLA) was observed in 37 $(36.3 \%)$ cases (28 males, 9 females). PLA prevalence was similar in men (36\%) and women (37.5\%). Of PLA cases, 19 (51\%) were unilateral (14 males, 5 females), and 18 (49\%) were bilateral (14 males, 4 females). In conclusion, PLA prevalence of $36.3 \%$ in our population was similar to other studies conducted in Iran. We found no gender difference in PLA prevalence and its patterns. Due to geographical variability in PLA rate, future regional and national studies with more magnificent sample sizes are recommended to determine the prevalence and gender-specific patterns of PLA.
\end{abstract}

\section{Introduction}

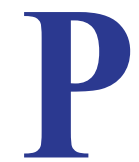

almaris Longus (PL) is a superficial muscle of the forearm, i.e., mainly tendinous and just a small portion of its length is composed of abdomen [1]. Its primary role is the augmentation of palmar fascia and serves as an accessory flexor of the wrist and abductor of the thumb [2]. The presence of this muscle is not necessary for hand function; it is naturally absent in some people [2]. Due to the easy surgical accessibility of PL, its anatomical characteristics, and negligible functional role, this muscle's tendon is used as a graft for various plastic and reconstructive surgeries [1]. Thus, Determining the prevalence of PL Absence (PLA) is of clinical significance, especially for surgeons who transplant the tendon of this muscle [3].

Referral textbooks report the rate of $15 \%$ for PLA in general populations [1]; however, a meta-analysis of relevant studies from different ethnicities calculated a general rate of $25 \%$ in this regard [4]. In this meta-analysis, the overall rate of PLA for different ethnicities was calculated as follow: $41.7 \%$ for Middle Eastern Arabs, $34.13 \%$ for Turks, $26.3 \%$ for Caucasians, $19.79 \%$ for South and Southeast Asians (including Iranians), 11.3\% for Africans, 4.5\% for East Asians, and 3.7\% for South Americans Amazon [4]. Associations between PLA and gender and body side have also been reported [5]. Commonly, research studies have used noninvasive physical

* Corresponding Author:

Fardin Fallah, MD.

Address: Legal Medicine Research Center, Legal Medicine Organization, Tehran, Iran.

Tel: +98 (21) 55614142

E-mail:fardin.fallah@gmail.com 
tests to determine the presence of PL; however, these tests are not as accurate as of the direct observation of the muscle during necropsy [5].

We investigated the prevalence rate of PLA by the necropsy of a series of cadavers in Zanjan City, Iran, during April-October 2009. Zanjan City is the capital of Zanjan Province at Northwest of Iran, and most of its inhabitants are of Azari ethnicity. Cadavers with the unnatural or doubtful causes of death from all regions of Zanjan Province are referred to the Central Legal Medicine Organization for necropsy. During the study period, 102 cadavers ( 78 males and 24 females) without any evidence of surgery, injury, or deformity in the forearm and hand were selected by convenience sampling method. After obtaining written informed consent from their guardians, they were bilaterally explored for PL. Cadavers with the evidence of decomposition and those referred after 24 hours of death were excluded from the study. Moreover, a horizontal incision with about 1-centimeter length was made in the central part of the proximal fold of both wrists; after skin and fascia dissection, areas abovemedian nerve as well as between the tendons of "Flexor Carpi Radialis" and "Flexor Digitorum Superficialis" were directly observed to find PL. After exploration, incisions were closed by sutures. The study was conducted by three experienced Forensic Medicine specialists. The age of study samples ranged from 8 to 69 years with the Mean (SD) of 35.87(11.77). Generally, PL was absent in 37 [36.3\% (95\% CI: 26.5\%-46.1\%)] cadavers (28 males and 9 females). The rates of unilateral and bilateral PLA were similar [18 (49\%) were bilateral, and 19 (51\%) were unilateral $(\mathrm{P}>0.9)]$. The rate of overall PLA was $36 \%$ for males and $37.5 \%$ for females. The anatomical characteristics of PLA according to the cadavers' gender are summarized in Table 1.

Our PLA prevalence rate of $36.3 \%$ was comparable with this rate in other regions of Iran $[6,7]$. The literature suggested several diverse monographs and PLA rates revealed wide regional and ethnical variability, from $0.6 \%$ in Korea [8] to $69.5 \%$ in Turkey [9]. Comparing the findings of these monographs, variations in sample sizes, age of the study participants, and study methods should be regarded. The majority of studies have used clinical tests to find PL muscles that are prone to bias and usually overestimate the rate of PLA, compared to necropsy, i.e., objective and more accurate [10]. Of the study, participants' age also varies in these monographs; however, as PL develops at birth [11], we assumed that age is not a confounder of PLA prevalence. This assumption was also confirmed in a study in Africa [12].

We found no significant gender difference in the prevalence of PLA, which is consistent with the other monographs of Iran [13] and other countries [14]. Some studies have reported a greater prevalence of PLA in females $[5,15]$; however, some have also demonstrated opposing results $[2,3]$. Pooling findings of these reports in a metaanalysis highlight a slightly higher prevalence of PL absence in females, which is not statistically significant [4].

Rates of unilateral and bilateral PLA were the same in our study population and the type of absence (unilateral or bilateral) was not associated with gender. These two findings are in line with the results of a recent meta-analysis [4]. Descriptive studies have demonstrated the predominance of both bilateral [15] and unilateral [5] PLA; however, studies that have applied statistical analysis reported no statistically significant lateral predominance of PLA [14].

We generally found the right-side dominance of PLA, which was due to this pattern among females (there was no side dominance in males). Furthermore, in this descriptive study, only 5 females with unilateral absence were included and the observed pattern among such small sample sizes is not generalizable. Studies with greater sample sizes in Iran and other countries have reported equal rates of PLA in left and right sides [6, 14 15]. A meta-analysis of relevant studies from various

Table 1. The anatomical characteristics of PLA according to the studied cadavers' gender

\begin{tabular}{|c|c|c|c|c|c|}
\hline \multirow{3}{*}{ Sex } & \multicolumn{3}{|c|}{ Types of PLA } & \multirow{3}{*}{ Total } & \multirow{3}{*}{$\mathbf{P}$} \\
\hline & \multicolumn{2}{|c|}{ Unilateral } & \multirow{2}{*}{ Bilateral } & & \\
\hline & Right-sided & Left-sided & & & \\
\hline Male: N (\%) & $7(25)$ & $7(25)$ & $14(50)$ & $28(100)$ & \multirow{2}{*}{$>0.9^{*}$} \\
\hline Female: N (\%) & $4(44.5)$ & 1 (11.1) & $4(44.5)$ & $9(100)$ & \\
\hline
\end{tabular}

* Fischer's exact test for comparing the rate of unilateral and bilateral absence between genders $\begin{aligned} & \text { International Journal of } \\ & \text { Medical Toxicology \& Forensic Medicine }\end{aligned}$ 
ethnicities demonstrated the predominance of left side PLA which was not gender-related [4].

\section{Conclusion}

Overall, the absence of PL in this cadaveric study was calculated as $36.3 \%$, and this rate was equal in both genders. Half of PLAs were unilateral, and half were bilateral, and this pattern was not associated with the cadavers' gender. Due to the ethical considerations and study limitations, we failed to include more cadavers; therefor, further studies with higher sample sizes could declare the general and gender-specific patterns of PLA in the Iranian population.

\section{Ethical Considerations}

\section{Compliance with ethical guidelines}

This study was approved by the Ethics Committee of Zanjan University of Medical Sciences, Zanjan, Iran, and the Ethics Committee of Legal Medicine Research Center of Iran.

\section{Funding}

This research did not receive any specific grant.

\section{Author's contributions}

Conceptualization: Mehdi Forouzesh, Abdolrazagh Barzegar; Methodology: All authors; Investigation: Mehdi Forouzesh.

\section{Conflicts of interest}

The authors declared no conflicts of interest.

\section{References}

[1] Erić M, Krivokuća D, Savović S, Leksan I, Vucinić N. Prevalence of the palmaris longus through clinical evaluation. Surgical and Radiologic Anatomy. 2010; 32(4):357-61. [DOI:10.1007/s00276-009-0573-0] [PMID]

[2] Ioannis D, Anastasios K, Konstantinos N, Lazaros K, Georgios N. Palmaris longus muscle's prevalence in different nations and interesting anatomical variations: Review of the literature. Journal of Clinical Medicine Research. 2015; 7(11):825-30. [DOI:10.14740/jocmr2243w] [PMID] [PMCID]

[3] Georgiev GP, Iliev AA, Dimitrova IN, Kotov GN, Malinova LG, Landzhov BV. Palmaris longus muscle variations: Clinical significance and proposal of new classifications. Folia
Medica. 2017; 59(3):289-97. [DOI:10.1515/folmed-2017-0035] [PMID]

[4] Yammine K. Clinical prevalence of palmaris longus agenesis: A systematic review and meta-analysis. Clinical Anatomy. 2013; 26(6):709-18. [DOI:10.1002/ca.22289] [PMID]

[5] Sankar KD, Bhanu PS, John SP. Incidence of agenesis of palmaris longus in the Andhra population of India. Indian Journal of Plastic Surgery. 2011; 44(1):134-8. [DOI:10.4103/09700358.81448] [PMID] [PMCID]

[6] Heshmati AA, Karbalaeikhani A, Saied A, Rouhani M Aboei M, Abroud F, et al. Assessment of the presence or absence of palmaris longus and the fifth superficial flexor tendon in the Iranian population: Are these tendons evolutionary? Middle East Journal of Family Medicine. 2017; 7(10):71-4 [DOI:10.5742/MEWFM.2017.92987]

[7] Jashni HK, Rahmanian K, Jahromi AS. Relation of palmaris longus agenesis with hand dominance. Life Sciences. 2014 11(2):161-3

[8] Ahn D, Yoon E, Koo S, Park S. A prospective study of the anatomic variations of the median nerve in the carpal tunnel in Asians. Annals of Plastic Surgery. 2000; 44(3):282-7. [DOI:10.1097/00000637-200044030-00006] [PMID]

[9] Ceyhan O, Mavt A. Distribution of agenesis of palmaris longus muscle in 12 to 18 years old age groups. Indian Journal of Medical Sciences. 1997; 51(5):156-60.

[10] Pekala PA, Henry BM, Pekala JR, Skinningsrud B, Walocha JA, Bonczar M, et al. Congenital absence of the palmaris longus muscle: A meta-analysis comparing cadaveric and functional studies. Journal of Plastic, Reconstructive \& Aesthetic Surgery. 2017; 70(12):1715-24. [DOI:10.1016/j. bjps.2017.08.002] [PMID]

[11] Agarwal P. Absence of the palmaris longus tendon in Indian population. Indian Journal of Orthopaedics. 2010 44(2):212-5. [DOI:10.4103/0019-5413.61863] [PMID] [PMCID]

[12] Venter G, Van Schoor AN, Bosman MC. Degenerative trends of the palmaris longus muscle in a South African population. Clinical Anatomy. 2014; 27(2):222-6. [DOI:10.1002/ ca.22226] [PMID]

[13] Nasiri E, Pourghasem M, Moladoust H. The prevalence of absence of the palmaris longus muscle tendon in the north of Iran: A comparative study. Iranian Red Crescent Medical Journal. 2016; 18(3):e22465. [DOI:10.5812/ircmj.22465]

[14] Sebastin SJ, Lim AY. Clinical assessment of absence of the palmaris longus and its association with other anatomical anomalies-a Chinese population study. ANNALS Academy of Medicine Singapore. 2006; 35(4):249-53. [PMID]

[15] Kose O, Adanir O, Cirpar M, Kurklu M, Komurcu M. The prevalence of absence of the palmaris longus: A study in Turkish population. Archives of Orthopaedic and Trauma Surgery. 2009; 129(5):609. 
This Page Intentionally Left Blank 